\title{
Médiévales
}

Langues, Textes, Histoire

51 | automne 2006

L'Occident sur ses marges ( $\left.\mathrm{V}\right|^{\mathrm{e}}-\mathrm{XI}^{\mathrm{e}}$ siècles)

\section{Bruno Dumézil, Les Racines chrétiennes de l'Europe. Conversion et liberté dans les royaumes barbares, $V^{e}-V_{I I I}$ siècles}

Paris, Fayard, 2005, 804 p.

\section{Stéphane Gioanni}

\section{(2) OpenEdition}

\section{Journals}

Édition électronique

URL : https://journals.openedition.org/medievales/1445

DOI : 10.4000/medievales. 1445

ISSN : 1777-5892

Éditeur

Presses universitaires de Vincennes

Édition imprimée

Date de publication : 1 décembre 2006

Pagination : 170-173

ISBN : 978-2-84292-193-4

ISSN : 0751-2708

Référence électronique

Stéphane Gioanni, «Bruno Dumézil, Les Racines chrétiennes de l'Europe. Conversion et liberté dans les royaumes barbares, $v^{e}$-VIII ${ }^{e}$ siècles », Médiévales [En ligne], 51 | automne 2006, mis en ligne le 12 mars 2007, consulté le 22 avril 2022. URL : http://journals.openedition.org/medievales/1445 ; DOI : https:// doi.org/10.4000/medievales. 1445

Ce document a été généré automatiquement le 22 avril 2022

Tous droits réservés 


\title{
Bruno Dumézil, Les Racines
} chrétiennes de l'Europe. Conversion et liberté dans les royaumes barbares, $V^{e}$ VIII siècles

\author{
Paris, Fayard, 2005, 804 p.
}

\section{Stéphane Gioanni}

1 Le livre de Bruno Dumézil se propose d'étudier les mécanismes de la conversion au catholicisme des royaumes barbares situés dans les anciennes provinces de l'Empire romain d'Occident entre le $\mathrm{v}^{\mathrm{e}}$ et le $\mathrm{VIII}^{\mathrm{e}}$ siècle. Les politiques civiles de coercitions religieuses menées par les autorités impériales n'étaient pas parvenues à imposer le christianisme nicéen dans l'ensemble de la pars occidentalis. Alors que la chute de l'Empire d'Occident aurait pu sonner le glas des christiana tempora, la domination des rois germaniques - dont aucun n'était catholique - se traduisit peu à peu par la disparition du paganisme et des hérésies chrétiennes. Pour expliquer la conversion inattendue des royaumes barbares à la foi de Nicée, Bruno Dumézil commence par définir les notions de "conversion», d'« évangélisation», de "mission», de « contrainte » et de « liberté » religieuse. Cette réflexion conceptuelle lui permet de se démarquer des diverses traditions historiographiques qui s'étaient focalisées sur la conversion de l'Empire romain au détriment des royaumes barbares d'Occident. Après avoir posé le cadre chronologique et géographique de son enquête, l'auteur développe une argumentation en trois parties destinées à identifier, dans chaque royaume, les différents mécanismes de la contrainte religieuse, des politiques brutales de persécution aux formes de coercition les plus subtiles, qui révèlent la collaboration croissante entre l'autorité religieuse (l'évêque) et le pouvoir politique (le roi).

2 La première partie (Pasteurs et troupeaux. Les Christiana tempora après l'Empire) examine les conditions favorables de la conversion après 476. Premier élément: les nouveaux maîtres du pouvoir se sont appliqués à conserver les "héritages» culturels et juridiques de l'époque impériale qui avaient assuré la pérennité du christianisme 
ancien. La politique du roi de Ravenne Théodoric est sans doute le meilleur exemple de l'attachement aux principes $\mathrm{du}$ droit romain (Code Théodosien, Constitutions sirmondiennes...). Deuxième élément: l'affaiblissement de l'autorité impériale, dès les années 430, avait dynamisé la vocation missionnaire des évêques qui étaient de plus en plus contraints d'assumer seuls l'impératif apostolique d'évangélisation face aux résistances païennes ou hérétiques. L'évolution de la fonction épiscopale renforça la position dominante de l'évêque-pasteur qui bénéficiait de nouveaux modes de contraintes dans la cité puisqu'il était chargé de la gestion de la vie civique et de l'encadrement de la vie sociale. Entouré des fidèles et des clercs, l'évêque devint ainsi l'acteur principal de l'évangélisation, comme l'exprime clairement Grégoire le Grand pour qui «le pouvoir épiscopal seul organise la conversion» (p.159). La mission apostolique de l'évêque se caractérisa à quelques exceptions près ( $c f$. le prosélytisme offensif de Sévère de Minorque) par des modalités de conversion de plus en plus pragmatiques, capables de déroger aux principes établis, par exemple en acceptant le mariage entre une catholique et un roi d'une autre religion (Caretène et Gondebaud ou encore Clotilde et Clovis...). Dernier élément : le combat contre les pratiques païennes, qui persistaient surtout dans les campagnes, fut facilité, après 476, par la disparition totale du paganisme au sein des anciennes élites impériales pour lesquelles «la conversion n'était plus une obligation légale, mais une nécessité de survie sociale » (p. 105). Durant toute «cette période d'apaisement sur le plan des modalités de la conversion " (p. 165), l'épiscopat pu ainsi élaborer une stratégie de conversion des peuples germaniques fondée d'abord sur la conversion de leur roi.

3 La deuxième partie (Le retour du roi. La conversion du souverain germanique et de son peuple) se concentre sur la conversion personnelle du roi et sur les tentatives d'unité religieuse entreprise par le roi converti. L'analyse comparative montre que ce processus varie en fonction de l'histoire de chaque royaume: dans le monde anglo-saxon, la rapidité de l'unification chrétienne s'expliqua en grande partie par la faiblesse des autres cultes et la fragilité de l'implantation païenne dans l'île ; dans le regnum Francorum, la conversion du royaume fut facilitée par la «remarquable continuité » (p.217) de la chrétienté catholique avec le monde romain; en revanche, dans l'Italie soumise aux dominations successives, l'arianisme tolérant des rois goths, le rêve d'unification de Justinien puis la volonté d'arianisation sous les Lombards retardèrent de deux siècles le processus de christianisation étatique. Nécessairement tributaire de l'histoire de chaque royaume, la " conversion nationale » dépendit surtout de l'évolution des rapports de force entre la royauté et l'épiscopat comme en témoignent les tentatives d'unification chrétienne de l'Espagne wisigothique : la disparition forcée de l'arianisme et du paganisme entreprise par Léovigild avait été suivie, sous le règne du roi Sisebut (612-621), d'une persécution systématique du judaïsme considéré comme le dernier corps étranger au royaume chrétien d'Espagne. Dans un premier temps, la réaction équivoque de l'épiscopat espagnol au « concile de Séville » illustra l'embarras d'Isidore partagé entre sa fidélité à Sisebut et son attachement à la vocation universelle de l'Église. Mais à la fin du viI siècle, les évêques furent les principaux soutiens de la politique du roi Egica contre les juifs. Le concile de Tolède XVII, en novembre 694, contribua à définir le judaïsme comme une hérésie ennemie de l'Église et de l'Espagne en confondant « en une même fides la foi religieuse et la fidélité civile». L'impossibilité d'assimiler les juifs dans l'unité politico-religieuse se traduisit alors par l'asservissement ou la conversion forcée des juifs auxquels mit fin la conquête de l'Espagne par les armées arabes en 711 qui permit à la religion juive de retrouver un statut d'existence légale dans le régime 
islamique. Dans cet exemple, la collaboration croissante entre le clergé et le roi montre comment l'épiscopat espagnol est passé d'une vocation universelle de l'Église, dont Isidore de Séville fut le dernier représentant, à l'ambition plus étriquée de servir la fondation d'un royaume chrétien. Bien que la transition religieuse ait suivi des voies et des rythmes variés suivant chaque royaume, elle se caractérise toutefois par des phases communes. La conversion du souverain germanique se traduit généralement, après une certaine défiance, par une législation du culte autorisant la prédication et par la réunion d'une assemblée de la nation encadrant le changement officiel. Une deuxième période est marquée par la situation délicate du roi converti tant d'un point de vue religieux que politique (l'échec militaire du roi Sigismond fut considéré comme la conséquence de sa conversion au catholicisme). Pour dissiper tout risque d'hostilité intérieure, les souverains sont alors contraints de mener une conversion nationale en collaboration avec l'épiscopat. L'ultime étape consacre la pérennisation de la "société chrétienne triomphante " marquée par l'unité religieuse du royaume et la christianisation des structures sociales.

La troisième partie (La société chrétienne. Mécanismes de définition d'une chrétienté occidentale) étudie la constitution proprement dite de la société chrétienne. Cette dernière condition de l'unification religieuse supposait l'établissement d'une norme religieuse destinée à intégrer ou, le cas échéant, à exclure. La définition de cette norme concernait autant les croyances que les pratiques du chrétien. L'uniformisation rituelle, qui supposait l'élimination de toute pratique hérétique ou païenne, fut accomplie grâce aux efforts conjugués du roi, des évêques mais aussi d'autres acteurs essentiels de l'évangélisation, à commencer par les fondations monastiques: l'expérience de saint Martin, qui avait refusé la violence pour convertir les païens, avait profondément marqué l'œuvre missionnaire des moines d'Occident, si différents sur ce point de leurs frères orientaux. L'évangélisation quotidienne des campagnes encouragée par Cassiodore à Vivarium, la pastorale des évêques provençaux nourrie de références au monachisme lérinien, la conversion sans violence promue par Grégoire le Grand ou encore la «théâtralisation de l'affrontement » illustrée par Colomban reflètent les différents types d'engagements monastiques dans l'unification religieuse de l'Occident. Les élites chrétiennes contribuèrent elles aussi à la christianisation en profondeur de l'Occident barbare en réalisant une "évangélisation par le haut». Les modes de supériorité économique et sociale (droit des propriétaires, autorité administrative, dépendances financières, clientélisme...) induisaient en effet des rapports de domination souvent plus contraignants - et donc plus efficaces - que la simple fidélité au monarque ou à l'évêque.

5 L'analyse de l'uniformisation religieuse de l'Occident barbare au cours des trois premiers siècles du Moyen Âge nous renseigne davantage sur les mécanismes que sur les causes de l'évangélisation de l'Europe. Toutefois, la collaboration entre les différents acteurs de la conversion révèle un fondement de l'organisation politique et religieuse de l'Europe pré-carolingienne. Le succès final du christianisme nicéen - la religion de Rome - souligne la permanence du modèle romain tout en montrant, par ses prétentions universelles, que l'unité politique n'est plus concevable sans unité religieuse. Au terme de cette enquête monumentale, on ne peut être qu'impressionné par l'efficacité de la démonstration. Certaines questions n'en restent pas moins ouvertes, comme le rappellent les dernières pages volontairement paradoxales de l'épilogue : les principaux acteurs de l'unification religieuse de l'Occident, de Salvien de Marseille à Bède le Vénérable, en passant par Théodoric, Grégoire ou Isidore qui 
« condamnaient l'usage de la contrainte », auraient eu, selon l'auteur, une perception aiguë de l'altérité religieuse qui oscille entre un "droit à la différence » et un « droit à l'erreur » : « même s'il n'y eut jamais de formulation de la liberté de conscience en tant que telle, il est évident qu'il exista, à certains moments et dans certains contextes, l'idée d'un droit à la différence " (p. 465). L'auteur aura sans doute l'occasion de préciser sa pensée sur ce problème complexe : l'œuvre de conversion implacable que reflète le code Théodosien nous rappelle en effet que les politiques de coercition impériale revêtaient déjà une palette de nuances qui n'impliquaient pas nécessairement un «droit à la différence». Contrairement à ce que fit plus tard Justinien, Théodose et ses premiers successeurs s'étaient refusés à lancer des persécutions contre les païens et les hérétiques qui menaçaient l'unité de l'Empire parce que, précisément, les persécutions s'étaient révélées inefficaces contre les chrétiens : pour mieux les faire disparaître, ils avait choisi de les marginaliser en asphyxiant progressivement leur culte et en les écartant peu à peu de la communauté civique. Mais cette comparaison verticale, qui pourrait être le seuil d'une nouvelle enquête, est marginale au regard de l'immense travail accompli dans ce livre. L'auteur complète sa démonstration en fin de volume par 179 pages de notes, un répertoire des sources et six annexes présentant le texte, la traduction et le commentaire de plusieurs documents essentiels (le Praeceptum de Childebert I ${ }^{\text {er }}$, les souscriptions du concile de Tolède III de 589, le carmen de synodo Ticinensi, les Lettres d'Avit relatives à la conversion du roi burgonde Sigismond...). En particulier, l'annexe 3 constitue un précieux florilège de textes qui permettent de reconstituer le contenu de l'édit de Sisebut, aujourd'hui perdu, sur la conversion forcée des juifs dans le royaume wisigothique. Le projet de Bruno Dumézil exigeait une lecture complète des sources narratives et diplomatiques mais aussi un sens aigu de la nuance et un effort de conceptualisation qui font de ce livre une contribution majeure à l'histoire des royaumes chrétiens d'Occident entre le $\mathrm{V}^{\mathrm{e}}$ et le VIII ${ }^{\mathrm{e}}$ siècle. 